\title{
Dynamic driving pressure associated mortality in acute respiratory distress syndrome with extracorporeal membrane oxygenation
}

\author{
Li-Chung Chiu ${ }^{1 *}$, Han-Chung Hu ${ }^{1,2,3}$, Chen-Yiu Hung ${ }^{1}$, Chih-Hao Chang ${ }^{1}$, Feng-Chun Tsai ${ }^{4}$, Cheng-Ta Yang ${ }^{1,2}$, \\ Chung-Chi Huang ${ }^{1,2,3}$, Huang-Pin $\mathrm{Wu}^{5}$ and Kuo-Chin Kao ${ }^{1,2,3}$
}

\begin{abstract}
Background: The survival predictors and optimal mechanical ventilator settings in patients with severe acute respiratory distress syndrome (ARDS) undergoing extracorporeal membrane oxygenation (ECMO) are uncertain. This study was designed to investigate the influences of clinical variables and mechanical ventilation settings on the outcomes for severe ARDS patients receiving ECMO.

Methods: We reviewed severe ARDS patients who received ECMO due to refractory hypoxemia from May 2006 to October 2015. Serial mechanical ventilator settings before and after ECMO and factors associated with survival were analyzed.

Results: A total of 158 severe ARDS patients received ECMO were finally analyzed. Overall intensive care unit (ICU) mortality was $55.1 \%$. After ECMO initiation, tidal volume, peak inspiratory pressure and dynamic driving pressure were decreased, while positive end-expiratory pressure levels were relative maintained. After ECMO initiation, nonsurvivors had significantly higher dynamic driving pressure until day 7 than survivors. Cox proportional hazards regression model revealed that immunocompromised [hazard ratio 1.957; 95\% confidence interval (CI) 1.216-3.147; $p=0.006$ ], Acute Physiology and Chronic Health Evaluation (APACHE) II score (hazard ratio 1.039; 95\% Cl 1.005-1.073; $p=0.023$ ), ARDS duration before ECMO (hazard ratio 1.002; 95\% Cl 1.000-1.003; $p=0.029$ ) and mean dynamic driving pressure from day 1 to 3 on ECMO (hazard ratio 1.070; 95\% Cl 1.026-1.116; $p=0.002$ ) were independently associated with ICU mortality.
\end{abstract}

Conclusions: For severe ARDS patients receiving ECMO, immunocompromised status, APACHE II score and the duration of ARDS before ECMO initiation were significantly associated with ICU survival. Higher dynamic driving pressure during first 3 days of ECMO support was also independently associated with increased ICU mortality.

Keywords: Driving pressure, Mechanical ventilation, Acute respiratory distress syndrome,

Extracorporeal membrane oxygenation, Outcome

\section{Background}

Acute respiratory distress syndrome (ARDS) is a heterogeneous syndrome with complex pathophysiologic mechanisms and has a high mortality rate up to $45 \%$ in severe ARDS [1]. A lung-protective ventilation strategy

\footnotetext{
*Correspondence: pomd54@cgmh.org.tw

${ }^{1}$ Department of Thoracic Medicine, Chang Gung Memorial Hospital, Chang Gung University College of Medicine, Linkou, No. 5, Fu-Shing St., Kwei-Shan, Taoyuan 886, Taiwan

Full list of author information is available at the end of the article
}

with lower tidal volume remains the cornerstone of treatment for ARDS and is associated with improved survival [2]. Many alternative rescue treatments had been investigated for ARDS with severe hypoxemia, but their impact on mortality is undetermined, except for early application of prolonged prone position [3].

Although the survival benefit is not well established, extracorporeal membrane oxygenation (ECMO) may be a salvage therapy for severe ARDS patients with profound hypoxemia refractory to conventional mechanical 
ventilation [4-6]. For severe ARDS patients receiving ECMO support, the positive result of a multicenter randomized controlled trial [7], favorable outcomes during the 2009 influenza A (H1N1) pandemic [8] and major advances in technology with less complication had allowed ECMO widespread application over the past decade $[5,9,10]$. However, the precise indications, optimal timing to initiate and factors associated with mortality for severe ARDS patients who received ECMO were still not well established $[4,6,9,11]$.

ECMO facilitates an ultra-protective ventilation of more lowering delivered tidal volume and airway pressure for resting the lungs. This ultra-protective lung strategy ideally may improve outcomes by further minimizing ventilator-induced lung injury (VILI) $[4,6,11-$ 16]. Although ECMO support limited stress and strain with ultra-protective ventilation, the specific extent of lung rest strategy and the optimal mechanical ventilation settings targets during ECMO for severe ARDS patients remained uncertain [11-16]. There was no large multicenter prospective randomized controlled trial to address the optimal mechanical ventilation settings during ECMO in severe ARDS patients. In most clinical practice, the mechanical ventilation settings during the ECMO depended on the clinicians' experience [6]. A recent study from 3562 patients with ARDS enrolled in 9 previous reported randomized controlled trials concluded that decreases in driving pressure were strongly associated with increased survival for patients with ARDS [17]. However, it is uncertain whether a similar association between driving pressure and survival exists for severe ARDS patients receiving ECMO.

The aim of this study was to investigate the influences of clinical variables and mechanical ventilation settings on the survival outcomes for severe ARDS patients receiving ECMO.

\section{Methods}

\section{Patient papulation}

This study was conducted in the medical and surgical ICUs at a tertiary care referral center, Chang Gung Memorial Hospital, with a 3700-bed general ward and a 278-bed adult ICU. The local Institutional Review Board for Human Research approved this study (CGMH IRB No. 201600632B0), and the need for informed consent was waived due to the retrospective nature of the study.

We analyzed severe ARDS patients who received ECMO for refractory hypoxemia between May 2006 and October 2015. Severe ARDS was defined by the Berlin definition with acute onset within 1 week, bilateral lungs opacities, no evidence of cardiac failure-related hydrostatic edema by echocardiography and $\mathrm{PaO}_{2} / \mathrm{FiO}_{2}$ ratio $<100 \mathrm{mmHg}$ with positive end-expiratory pressure
(PEEP) $\geq 5 \mathrm{~cm} \mathrm{H}_{2} \mathrm{O}$ [1]. Exclusion criteria were: (1) age $<20$ years, (2) malignancies with poor prognosis within 5 years and (3) significant underlying comorbidities or severe multiple organ failure refractory to treatment (4) mortality within $24 \mathrm{~h}$ after ECMO initiation. Before consideration of ECMO initiation, all patients were sedated and ventilated with pressure-controlled ventilation using tidal volume of $6-8 \mathrm{ml} / \mathrm{kg}$ predicted body weight ( $\mathrm{PBW}$ ).

\section{ECMO management and protocol}

The decision to initiate ECMO was made by treating intensive care specialist when persistent hypoxemia $\left(\mathrm{PaO}_{2} / \mathrm{FiO}_{2}\right.$ ratio $\left.<80 \mathrm{mmHg}\right)$ at least $6 \mathrm{~h}$, despite aggressive mechanical ventilation support $(\mathrm{PEEP}>10$ $\mathrm{cm} \mathrm{H}_{2} \mathrm{O}$ or peak inspiratory pressure $>35 \mathrm{~cm} \mathrm{H}_{2} \mathrm{O}$ ). All patients were deeply sedated and paralyzed with continuous neuromuscular blocking agent and ventilated with pressure-controlled ventilation until weaning attempt from ECMO. Initial mechanical ventilator settings protocol after ECMO support were as follows: tidal volume 4-6 ml/kg PBW; PEEP 10-15 $\mathrm{cm} \mathrm{H}_{2} \mathrm{O}$; peak inspiratory pressure $25-30 \mathrm{~cm} \mathrm{H}_{2} \mathrm{O}$; respiratory rate $10-12$ breaths per minute; and $\mathrm{FiO}_{2}$ adjusted to maintain arterial oxygen saturation above $90 \%$. The criteria for weaning from ECMO in our experience were resolving lungs infiltration, lung compliance $>20 \mathrm{ml} / \mathrm{cm} \mathrm{H}_{2} \mathrm{O}, \mathrm{PaO}_{2}>60 \mathrm{mmHg}$ and $\mathrm{PaCO}_{2}<45 \mathrm{mmHg}$ under $\mathrm{FiO}_{2} \leqq 0.4$, PEEP $\leqq 6-8 \mathrm{~cm}$ $\mathrm{H}_{2} \mathrm{O}$, and peak inspiratory pressure $\leqq 30 \mathrm{~cm} \mathrm{H}_{2} \mathrm{O}$.

\section{Data collection}

The following data were collected from the hospital chart and analyzed: age, sex, body weight, body mass index, etiologies of ARDS, underlying diseases, Acute Physiology and Chronic Health Evaluation (APACHE) II score, Sequential Organ Failure Assessment (SOFA) score and lung injury score on the day of ICU admission.

Arterial blood gas, ARDS duration before ECMO, ventilator settings included tidal volume, respiratory rate, PEEP, peak inspiratory pressure, dynamic driving pressure (the difference between peak inspiratory pressure and PEEP) and $\mathrm{FiO}_{2}$ were recorded before ECMO initiation. After ECMO support, daily arterial blood gas, ventilator settings, ECMO settings (gas flow, blood flow and $\mathrm{FiO}_{2}$ ) and ECMO complications (oxygenator failure, blood clots in oxygenator or circuit, bleeding, infection or others) were recorded until ICU discharge.

\section{Statistical analyses}

Continuous variables were presented as means \pm standard deviation or median (interquartile range), and categorical variables were reported as numbers (percentages). Student's $t$ test or the Mann-Whitney $U$ test was used to compare continuous variables between survivors 
and nonsurvivors, as appropriate. Categorical variables were tested using Chi-square test for equal proportion or Fisher's exact test. Risk factors associated with ICU mortality were analyzed using Cox proportional hazards regression model with stepwise selection procedure. All variables that were related to ICU mortality with a $p<0.20$ were finally introduced in the model. Calibration was assessed using Hosmer-Lemeshow goodnessof-fit test (C statistic, goodness of fit was defined as a $p$ value $>0.05$ ), and discrimination was assessed by the area under the receiver operating characteristics curve. Cutoff points were calculated by obtaining the best Youden index (sensitivity + specificity -1 ). The results were presented as hazard ratio (HR) [95\% confidence interval (CI)]. Cumulative survival curves as a function of time were generated using the Kaplan-Meier approach and compared using the log-rank test. All statistical analyses were performed with SPSS 21.0 statistical software. A $p$ value $<0.05$ was considered significant.

\section{Results}

During the study period, 2622 patients were admitted to our ICUs with a diagnosis of ARDS, of whom 165 patients with severe ARDS receiving ECMO were included. A total of 158 patients were finally analyzed (Fig. 1). The overall ICU survival rate was $44.9 \%$.

Details of the demographic data, clinical characteristics and ventilator settings before ECMO initiation between survivors and nonsurvivors are presented in Table 1. The main cause of ARDS was bacterial pneumonia, followed by viral pneumonia. Survivors were younger and had less immunocompromised and lower baseline APACHE II, SOFA scores than nonsurvivors. The duration of ARDS before ECMO initiation was significantly shorter in survivors than nonsurvivors. Mechanical ventilation settings and other ventilation parameters before ECMO support in two groups did not show significantly difference. Venovenous ECMO was used for 120 patients (75.9\%), and other 38 patients received venoarterial ECMO with 11 patients shifted to venovenous ECMO later. Venoarterial ECMO was performed for heart failure with intractable shock complicating ARDS-related diseases. The median duration of ECMO, ventilator, ICU and hospital stay were 9 (5-15), 20 (12-38), 23 (13-43) and 39 (21-64) days, respectively. Overall, $43(27.2 \%)$ patients had one or more ECMO-related complications with 4 patients died due to intracranial hemorrhage.

\section{Mechanical ventilator settings after ECMO support}

Daily arterial blood gas, mechanical ventilation settings were recorded, and we analyzed the data at $6 \mathrm{~h}$, day 1 , 2, 3 and 7 after ECMO initiation. After ECMO support, tidal volume was reduced, but did not reveal significantly difference between survivors and nonsurvivors until day 7. After ECMO support $6 \mathrm{~h}$, survivors had significant higher PEEP level than nonsurvivors $(12.6 \pm 3.3$ vs. $11.4 \pm 3.1 \mathrm{~cm} \mathrm{H}_{2} \mathrm{O}, p=0.02$ ), but there was no difference until day 7 . Both peak inspiratory pressure and dynamic driving pressure were decreased after ECMO initiation. Nonsurvivors had significantly higher peak inspiratory pressure after ECMO support day 2, day 3 and day 7 ( $32.8 \pm 6.4$ vs. $30.6 \pm 5.2 \mathrm{~cm} \mathrm{H}_{2} \mathrm{O}, p=0.02 ; 32.9 \pm 6.8$ vs. $30.4 \pm 6.0 \mathrm{~cm} \mathrm{H}_{2} \mathrm{O}, p=0.02 ; 33.1 \pm 7.1$ vs. $29.8 \pm 5.7$ $\mathrm{cm} \mathrm{H}_{2} \mathrm{O}, p=0.01$ ). Nonsurvivors also had significantly higher dynamic driving pressure after ECMO support until day 7 (all $p<0.05$ ) (Table 1; Fig. 2).

\section{Outcomes analysis}

Cox proportional hazards regression model was used to identify variables that have prognostic value for ICU mortality (Table 2). Immunocompromised status, APACHE II score, ARDS duration before ECMO and mean dynamic driving pressure from day 1 to 3 on ECMO remained independently associated with ICU mortality. Dynamic driving pressure with a cutoff point of $21 \mathrm{~cm} \mathrm{H} \mathrm{H}_{2} \mathrm{O}$ exhibited the best Youden index, and mean dynamic driving pressure greater than $21 \mathrm{~cm} \mathrm{H}_{2} \mathrm{O}$ from day 1 to 3 on ECMO was associated with higher mortality (HR 2.553; 95\% CI 1.607-4.054; $p<0.001$; data not shown). Peak inspiratory pressure and SOFA score were not retained in the final model due to highly correlated with dynamic driving pressure and APACHE II score, respectively. Time to ECMO removal analysis and a landmark analysis excluding 7 patients who died in the first $24 \mathrm{~h}$ after ECMO revealed that severe ARDS patients with mean dynamic driving pressure $\leqq 21 \mathrm{~cm} \mathrm{H}_{2} \mathrm{O}$ had significantly higher rate of ECMO removal than those with mean dynamic driving pressure $>21 \mathrm{~cm} \mathrm{H}_{2} \mathrm{O}$ from day 1 to 3 on ECMO ( $p=0.017$, log-rank test) (Fig. 3). The overall survival rate of severe ARDS patients with mean dynamic driving pressure $\leqq 21 \mathrm{~cm} \mathrm{H}_{2} \mathrm{O}$ was significantly higher than those with mean dynamic driving pressure $>21 \mathrm{~cm} \mathrm{H}_{2} \mathrm{O}$ from day 1 to 3 on ECMO (56.1 vs. $33.3 \%, p=0.001$, log-rank test) (Fig. 4).

\section{Discussion}

Our study analyzed the serial ventilator settings changes in severe ARDS patients after ECMO support and found that increased dynamic driving pressure during the first 3 days was independently associated with higher mortality. In addition, immunocompromised status, APACHE II score and the duration of ARDS before ECMO initiation were also significantly associated with survival.

Amato and colleagues analyzed nine randomized controlled trials in ARDS patients and concluded that driving pressure was most strong predictor of mortality [17]. 
Severe respiratory failure patients receiving ECMO $(n=165)$

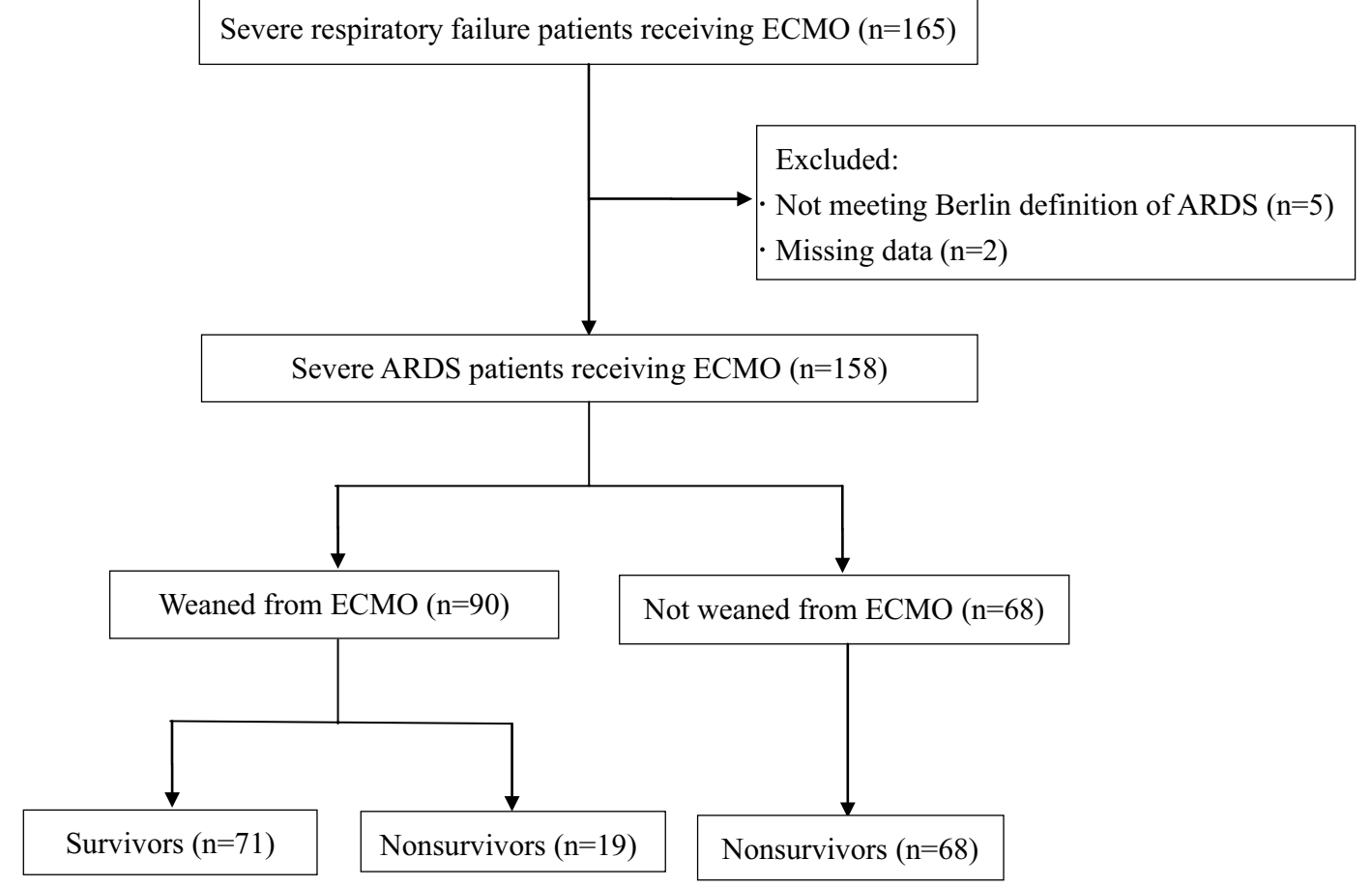

Fig. 1 Flowchart of severe acute respiratory distress syndrome (ARDS) patients receiving extracorporeal membrane oxygenation (ECMO)

Recent study also demonstrated decreased respiratory system and transpulmonary driving pressure were associated with improved 28-day mortality in ARDS patients [18]. A prospective multicenter study in 15 moderate ARDS patients with low-flow extracorporeal carbon dioxide removal $\left(\mathrm{ECCO}_{2} \mathrm{R}\right)$ demonstrated that driving pressure was significantly reduced during the first two days compared to baseline $[19,20]$. However, the role of driving pressure on the severe ARDS patients requiring ECMO was uncertain, and a clinical review recommended that driving pressure is important determinant of outcome during ECMO [6]. The present study in severe ARDS patients receiving ECMO revealed that dynamic driving pressure from day 1 to 3 on ECMO was independently associated with mortality (Table 2).

Driving pressure was inversely proportional to compliance of respiratory system and had two common definitions: the difference between plateau pressure and PEEP and the difference between peak inspiratory pressure and PEEP [21]. There was no study compared different modes of ventilation during ECMO, and pressurecontrolled mode appears to be advocated [12]. With pressure-controlled ventilation, pressure is maintained constant throughout inspiration, and flow decreases during inspiration and is often followed by a period of zero flow at end inspiration. Peak inspiratory pressure and peak alveolar pressure (plateau pressure) may be equal during no flow status [22]. Therefore, we used the difference between peak inspiratory pressure and PEEP as calculation of "dynamic" driving pressure. In fact, the most correct form can be obtained using transpulmonary driving pressure by esophageal manometry, but it is not easy to use in clinical practice. Reduction in dynamic driving pressure were found after ECMO initiation, and the values of survivors continued decreasing and exhibited significantly lower than nonsurvivors until day 7 (Fig. 2). Better lungs compliance and larger proportion of recovered functional lung size could have benefitted the survivors. Manipulation of driving pressure could be applied for ventilator management beside by adjusting the tidal volume and PEEP [18]. Although standardized ventilation protocol for ARDS patients before and after ECMO was followed, it remains unclear from our observational study to definitely conclude that driving pressure was causally related to outcome or simply another marker for ARDS severity and it needed further randomized controlled trials to confirm our findings.

Although ECMO facilitates the use of lung-protective ventilation, the optimal mechanical ventilation management is unknown [4, 6, 11-14]. The lowering levels of plateau pressure and tidal volume have been related to decreased mortality [16]. Therefore, an ultra-protective ventilation strategy with low tidal volume reduction $(<4 \mathrm{ml} / \mathrm{kg}, \mathrm{PBW})$, airway pressure reduction and 
Table 1 Characteristics of survivors and nonsurvivors of severe ARDS patients with ECMO support

\begin{tabular}{|c|c|c|c|c|}
\hline Characteristic & All patients $(n=158)$ & Survivors $(n=71)$ & Nonsurvivors $(n=87)$ & $p$ value \\
\hline Age (years) & $50.3 \pm 16.3$ & $46.0 \pm 16.5$ & $53.8 \pm 15.4$ & 0.003 \\
\hline Male (gender) & $108(68.4 \%)$ & $48(67.6 \%)$ & $60(69 \%)$ & 0.855 \\
\hline Body weight (kg) & $68.5 \pm 16.7$ & $70.1 \pm 17.4$ & $67.1 \pm 16.1$ & 0.268 \\
\hline Body mass index $\left(\mathrm{kg} / \mathrm{m}^{2}\right)$ & $25.8 \pm 5.2$ & $26.0 \pm 5.8$ & $25.6 \pm 4.7$ & 0.656 \\
\hline \multicolumn{5}{|l|}{ ARDS etiologies } \\
\hline Bacterial pneumonia & 55 (34.8\%) & $19(26.8 \%)$ & $36(41.4 \%)$ & 0.055 \\
\hline Viral pneumonia & $24(15.2 \%)$ & $13(18.3 \%)$ & $11(12.6 \%)$ & 0.327 \\
\hline Nonpulmonary sepsis & $21(13.3 \%)$ & $4(5.6 \%)$ & $17(19.5 \%)$ & 0.017 \\
\hline Pulmonary contusion & $19(12 \%)$ & $13(18.3 \%)$ & $6(6.9 \%)$ & 0.028 \\
\hline Aspiration pneumonia & $11(7 \%)$ & $8(11.3 \%)$ & $3(3.4 \%)$ & 0.066 \\
\hline Other causes & $28(17.7 \%)$ & $14(19.7 \%)$ & $14(16.1 \%)$ & 1.0 \\
\hline \multicolumn{5}{|l|}{ Comorbidities } \\
\hline Diabetes mellitus & $40(25.3 \%)$ & $23(32.4 \%)$ & $17(19.5 \%)$ & 0.065 \\
\hline Cerebrovascular accident & $10(6.3 \%)$ & $6(8.5 \%)$ & $4(4.6 \%)$ & 0.346 \\
\hline Chronic heart disease $^{a}$ & 55 (34.8\%) & $23(32.4 \%)$ & $32(36.8 \%)$ & 0.565 \\
\hline Chronic lung disease ${ }^{b}$ & $16(10.1 \%)$ & $4(5.6 \%)$ & $12(13.8 \%)$ & 0.115 \\
\hline Chronic liver disease $^{c}$ & $22(13.9 \%)$ & $6(8.5 \%)$ & $16(18.4 \%)$ & 0.073 \\
\hline Chronic kidney disease $^{d}$ & $18(11.4 \%)$ & $8(11.3 \%)$ & $10(11.5 \%)$ & 0.964 \\
\hline Immunocompromised ${ }^{e}$ & $42(26.6 \%)$ & $11(15.5 \%)$ & $31(35.6 \%)$ & 0.004 \\
\hline APACHE II score & $23.4 \pm 7.5$ & $21.8 \pm 8.0$ & $24.7 \pm 6.9$ & 0.014 \\
\hline SOFA score & $10.9 \pm 3.2$ & $10.3 \pm 3.1$ & $11.4 \pm 3.2$ & 0.042 \\
\hline Lung injury score & $3.37 \pm 0.44$ & $3.44 \pm 0.43$ & $3.32 \pm 0.45$ & 0.085 \\
\hline ARDS duration before ECMO (h) & $28.0(7.0-129.0)$ & $9.8(3.7-64.0)$ & $54.0(16.0-200.0)$ & $<0.001$ \\
\hline \multicolumn{5}{|l|}{ Pre-ECMO ventilator settings } \\
\hline $\mathrm{PaO}_{2} / \mathrm{FiO}_{2}(\mathrm{mmHg})$ & $64(52-87)$ & $64(53-80)$ & $63(52-107)$ & 0.198 \\
\hline Tidal volume (ml/kg PBW) & $7.7 \pm 2.4$ & $7.7 \pm 2.3$ & $7.8 \pm 2.4$ & 0.753 \\
\hline PEEP $\left(\mathrm{cm} \mathrm{H}_{2} \mathrm{O}\right)$ & $12.0 \pm 2.8$ & $12.2 \pm 2.5$ & $11.8 \pm 3.0$ & 0.319 \\
\hline Peak inspiratory pressure $\left(\mathrm{cm} \mathrm{H}_{2} \mathrm{O}\right)$ & $33.9 \pm 6.5$ & $33.6 \pm 6.0$ & $34.1 \pm 6.8$ & 0.645 \\
\hline Mean airway pressure $\left(\mathrm{cm} \mathrm{H}_{2} \mathrm{O}\right)$ & $18.7 \pm 4.4$ & $18.4 \pm 4.2$ & $18.9 \pm 4.6$ & 0.539 \\
\hline Dynamic driving pressure $\left(\mathrm{cm} \mathrm{H}_{2} \mathrm{O}\right)$ & $21.9 \pm 6.2$ & $21.1 \pm 5.8$ & $22.6 \pm 6.5$ & 0.139 \\
\hline Dynamic compliance $\left(\mathrm{ml} / \mathrm{cm} \mathrm{H}_{2} \mathrm{O}\right)$ & $22.5 \pm 11.2$ & $23.4 \pm 11.6$ & $21.7 \pm 10.9$ & 0.366 \\
\hline \multicolumn{5}{|l|}{ Pre-ECMO blood gas } \\
\hline $\mathrm{pH}$ & $7.28 \pm 0.14$ & $7.27 \pm 0.12$ & $7.28 \pm 0.15$ & 0.842 \\
\hline $\mathrm{PaCO}_{2}(\mathrm{mmHg})$ & $52.2 \pm 18.8$ & $50.7 \pm 19.6$ & $53.5 \pm 18.2$ & 0.359 \\
\hline $\mathrm{PaO}_{2}(\mathrm{mmHg})$ & $73.3 \pm 39.3$ & $71.6 \pm 39.2$ & $74.8 \pm 39.6$ & 0.617 \\
\hline Saturation (\%) & $84.4 \pm 15.9$ & $84.7 \pm 12.7$ & $84.1 \pm 18.2$ & 0.804 \\
\hline \multicolumn{5}{|c|}{ Ventilator settings from day 1 to 3 on ECMO } \\
\hline $\mathrm{PaO}_{2} / \mathrm{FiO}_{2}(\mathrm{mmHg})$ & $178(131-240)$ & $200(146-247)$ & $165(124-212)$ & 0.588 \\
\hline Tidal volume (ml/kg PBW) & $6.0 \pm 2.2$ & $6.1 \pm 2.0$ & $6.0 \pm 2.4$ & 0.914 \\
\hline $\operatorname{PEEP}\left(\mathrm{cm} \mathrm{H}_{2} \mathrm{O}\right)$ & $12.0 \pm 3.3$ & $12.3 \pm 3.2$ & $11.7 \pm 3.3$ & 0.202 \\
\hline Peak inspiratory pressure $\left(\mathrm{cm} \mathrm{H}_{2} \mathrm{O}\right)$ & $31.7 \pm 5.6$ & $30.6 \pm 5.1$ & $32.8 \pm 5.9$ & 0.018 \\
\hline Mean airway pressure $\left(\mathrm{cm} \mathrm{H}_{2} \mathrm{O}\right)$ & $17.7 \pm 4.0$ & $17.4 \pm 3.6$ & $17.9 \pm 4.3$ & 0.406 \\
\hline Dynamic driving pressure $\left(\mathrm{cm} \mathrm{H}_{2} \mathrm{O}\right)$ & $19.8 \pm 6.3$ & $18.3 \pm 6.0$ & $21.1 \pm 6.4$ & 0.006 \\
\hline
\end{tabular}

adequate PEEP was suggested to mitigate further VILI [4, 11-14]. Mechanical ventilation during ECMO may have an important impact on mortality. A cohort study of influenza A (H1N1)-induced ARDS patients receiving ECMO revealed that higher plateau pressure on the first day under ECMO was significantly associated with increased ICU mortality [23]. Another retrospective study demonstrated that higher PEEP levels during the first 3 days on ECMO were independently associated with lower ICU mortality [24]. A systemic review summarized 
Table 1 continued

\begin{tabular}{lllll}
\hline Characteristic & All patients $(\boldsymbol{n}=\mathbf{1 5 8})$ & Survivors $(\boldsymbol{n = 7 1 )}$ & Nonsurvivors $(\boldsymbol{n}=\mathbf{8 7})$ & $\boldsymbol{p}$ value \\
\hline Dynamic compliance $\left(\mathrm{ml} / \mathrm{cm} \mathrm{H}_{2} \mathrm{O}\right)$ & $19.2 \pm 8.1$ & $21.1 \pm 7.7$ & $17.4 \pm 8.1$ & 0.006 \\
Duration of ECMO (days) & $9.0(4.8-14.6)$ & $8.7(5.0-13.0)$ & $9.8(4.7-16.1)$ & 0.696 \\
ECMO complications & $43(27.2 \%)$ & $16(22.5 \%)$ & $27(31.0 \%)$ & 0.232
\end{tabular}

Data are presented as mean \pm standard deviation, count or median (interquartile range)

APACHE Acute Physiology and Chronic Health Evaluation, ARDS acute respiratory distress syndrome, ECMO extracorporeal membrane oxygenation, FiO fraction of inspired oxygen, $\mathrm{PaCO}_{2}$ partial pressure of carbon dioxide in arterial blood, $\mathrm{PaO}_{2}$ partial pressure of oxygen in arterial blood, $P B W$ predicted body weight, $P E E P$ positive end-expiratory pressure, SOFA Sequential Organ Failure Assessment. Dynamic driving pressure: (peak inspiratory pressure-PEEP)

a Chronic heart disease included chronic heart failure, valvular heart disease, arrhythmia, hypertension and coronary artery disease

b Chronic lung disease included chronic obstructive pulmonary disease, interstitial lung disease, tuberculosis and bronchiectasis

c Chronic liver disease included chronic hepatitis and cirrhosis

d Chronic kidney disease included chronic renal insufficiency with creatinine level above $1.5 \mathrm{mg} / \mathrm{dl}$

e Immunocompromised included hematological malignancies, solid tumors, sold organ transplantation, long-term steroid or immunosuppressant use and human immunodeficiency virus infection

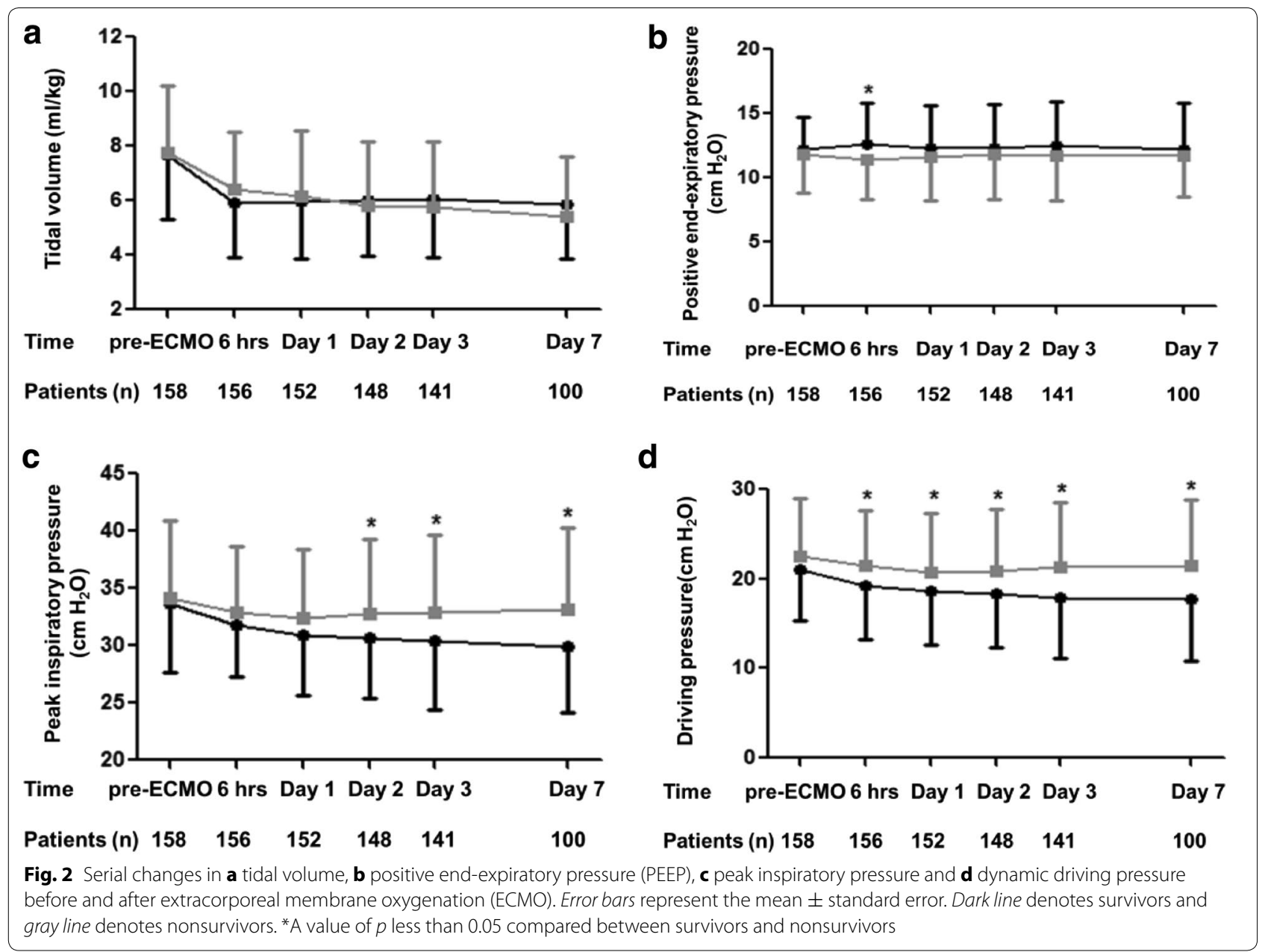

ventilation practices in ARDS patients with ECMO, and mortality was lower among patients who had lower ventilation intensity following ECMO initiation [14]. Our present study found that pre-ECMO ventilator settings exhibited no significant difference. After ECMO initiation, tidal volume, peak inspiratory pressure and dynamic driving pressure were all decreased, while PEEP levels were relative maintained. Dynamic driving pressure 
Table 2 Cox proportional hazards regression model with ICU mortality as outcome

\begin{tabular}{lll}
\hline Factors & Hazard ratio (95\% Cl) & $p$ value \\
\hline Univariate analysis & & \\
Age & $1.011(0.998-1.025)$ & 0.108 \\
Pulmonary contusion & $0.417(0.181-0.958)$ & 0.039 \\
Aspiration pneumonia & $0.405(0.128-1.285)$ & 0.125 \\
Diabetes mellitus & $0.635(0.373-1.083)$ & 0.096 \\
Chronic liver disease & $1.611(0.931-2.788)$ & 0.088 \\
Immunocompromised & $1.731(1.115-2.689)$ & 0.015 \\
APACHE II score & $1.032(1.004-1.062)$ & 0.027 \\
Lung injury score & $0.596(0.374-0.951)$ & 0.030 \\
ARDS duration before ECMO & $1.002(1.001-1.003)$ & 0.001 \\
Mean PEEP from day 1 to 3 on ECMO & $0.942(0.877-1.013)$ & 0.106 \\
Mean dynamic driving pressure from day 1 to 3 on ECMO & $1.052(1.015-1.090)$ & 0.005 \\
Mean dynamic compliance from day 1 to 3 on ECMO & $0.971(0.941-1.002)$ & 0.069 \\
Multivariate analysis & & \\
Immunocompromised & $1.957(1.216-3.147)$ & 0.006 \\
APACHE II score & $1.039(1.005-1.073)$ & 0.023 \\
ARDS duration before ECMO & $1.002(1.000-1.003)$ & 0.029 \\
Mean dynamic driving pressure from day 1 to 3 on ECMO & $1.070(1.026-1.116)$ & 0.002 \\
\hline APACHEAcute Physiogy and
\end{tabular}

APACHE Acute Physiology and Chronic Health Evaluation, ARDS acute respiratory distress syndrome, Cl confidence interval, ECMO extracorporeal membrane oxygenation, ICU intensive care unit, PEEP positive end-expiratory pressure. Dynamic driving pressure: (peak inspiratory pressure-PEEP)

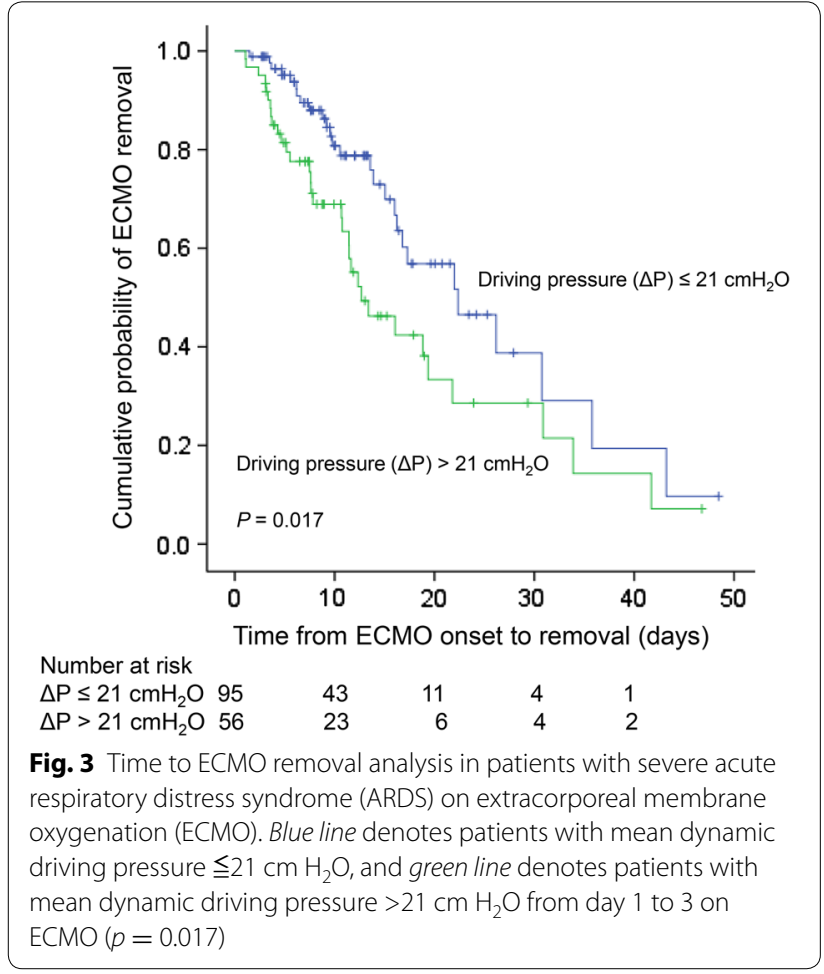

during first 3 days of ECMO support was independently related to ICU mortality. Whether these mechanical settings affected the outcome was not well known, and more

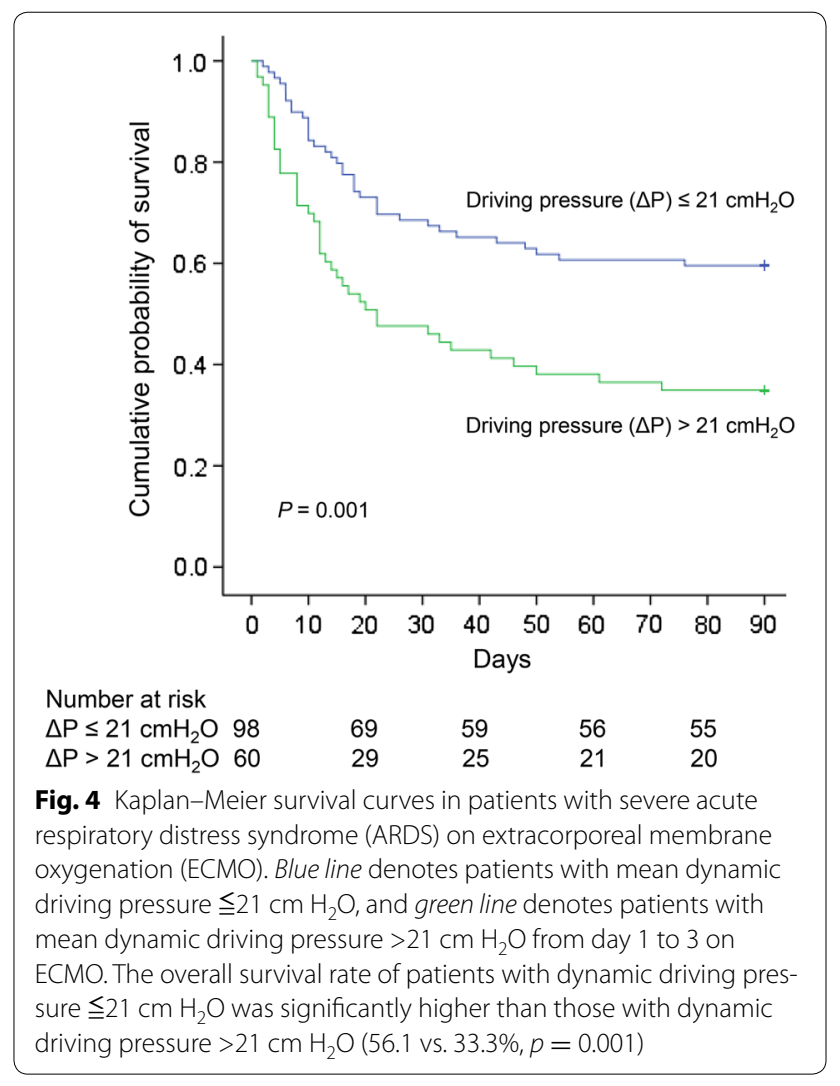


information will be obtained from an ongoing study in the future (SOLVE ARDS: Strategies for Optimal Lung Ventilation in ECMO for ARDS; clinicaltrials.gov identifier NCT01990456).

Several studies had investigated the predictors of mortality for severe ARDS patients treated with ECMO [10, 23-27]. Our study found that the duration of ARDS, APACHE II score and immunocompromised status before ECMO were independently associated with ICU mortality. The optimal timing for ECMO initiation had not been established, and mechanical ventilation may cause substantial VILI even under lung-protective strategy, which is worsened by delaying ECMO application for refractory hypoxemia $[4,13,26-28]$. Previous studies manifested duration of mechanical ventilation prior to ECMO support was correlated with mortality [10, 24-27]. Our study found that survivors had significantly shorter ARDS duration before ECMO. Several studies reported that degree of systemic organ failure was correlated with outcome for ARDS patients before ECMO initiation $[6,24-26,29,30]$, and we found that APACHE II score was significantly associated with ICU mortality. Furthermore, recent report included 2355 patients with severe ARDS receiving ECMO from multiple countries over a 13-year period concluded that immunocompromised status was independently associated with hospital survival [10]. Immunocompromised status was independently associated with long-term outcomes form severe ARDS patients with ECMO [25]. Our study also found that immunocompromised status was significantly related to ICU mortality.

There were several limitations of our study. First, this study is a retrospective analysis in one referral medical center, which may limit the generalization to other ICUs or hospitals. Besides, there might be residual and unmeasured confounding variables not included in our study and other biases during long period of study from 2006 to 2015 that could influence outcome. Second, APACHE II score was assessed only on the day of ICU admission and may not really reflect the dynamics of critical illness and treatment response. Serial evaluation of organ dysfunction during study period may be a better predictor of prognosis. Third, early application of prolonged prone position for severe ARDS patients as rescue therapy had survival benefit, but only a small number of our patients $(n=2)$ underwent prone position before ECMO. Finally, although ultra-protective ventilation strategy with ECMO based on a tidal volume reduction $(<4 \mathrm{ml} / \mathrm{kg}, \mathrm{PBW})$, our study showed relatively higher tidal volume (around $6 \mathrm{ml} / \mathrm{kg}$, PBW) after ECMO support.

\section{Conclusions}

Our study found that immunocompromised status, APACHE II score and the duration of ARDS before ECMO initiation were significantly associated with ICU survival in severe ARDS patients with ECMO. Dynamic driving pressure during first 3 days of ECMO support was also independently related to ICU mortality. Further large multicenter, prospective randomized controlled trials are necessary to confirm the hypothesis that dynamic driving pressure could be a better predictor for survival in severe ARDS patients with ECMO support.

\section{Abbreviations \\ APACHE: Acute Physiology and Chronic Health Evaluation; ARDS: acute respira- tory distress syndrome; Cl: confidence interval; ECMO: extracorporeal mem- brane oxygenation; HR: hazard ratio; ICU: intensive care unit; PBW: predicted body weight; PEEP: positive end-expiratory pressure; SOFA: Sequential Organ Failure Assessment; VILI: ventilator-induced lung injury.}

\section{Authors' contributions}

LCC and KCK took responsibility for the accuracy of the data analysis and drafting manuscript. $\mathrm{HCH}, \mathrm{CYH}, \mathrm{CHC}$ performed study design and data acquisition. FCT and CTY were responsible for primary data analysis. CCH and HPW performed interpretation of the results. All authors read and approved the final manuscript.

\section{Author details \\ ${ }^{1}$ Department of Thoracic Medicine, Chang Gung Memorial Hospital, Chang Gung University College of Medicine, Linkou, No. 5, Fu-Shing St., Kwei-Shan, Taoyuan 886, Taiwan. ${ }^{2}$ Department of Respiratory Therapy, Chang Gung Memorial Hospital, Chang Gung University College of Medicine, Taoyuan, Taiwan. ${ }^{3}$ Department of Respiratory Therapy, Chang Gung University College of Medicine, Taoyuan, Taiwan. ${ }^{4}$ Division of Cardiovascular Surgery, Chang Gung Memorial Hospital, Taoyuan, Taiwan. ${ }^{5}$ Division of Pulmonary, Critical Care and Sleep Medicine, Chang Gung Memorial Hospital, Keelung, Taiwan.}

\section{Acknowledgements}

The authors would like to thank Chiu-Hua Wang and Shin-Wen Bai for data management and appreciate the patients and staff of ICUs at Chang Gung Memorial Hospital. We thank Mr. Yu-Jr Lin in Clinical Informatics and Medical Statistics Research Center, Chang Gung Memorial Hospital, for validating and confirming all the statistics in this study.

\section{Competing interests}

The authors declare that they have no competing interests.

\section{Availability of data and materials}

The datasets supporting the conclusions of this article are included within the article.

\section{Consent for publication}

Written informed consent was not obtained for publication of these data due to the retrospective nature of the study.

\section{Ethics approval and consent to participate}

The Institutional Review Board of Chang Gung Medical Foundation approved the retrospective clinical data collection (CGMH IRB No. 201600632B0), and no consents were required for this type of study.

Received: 16 October 2016 Accepted: 16 January 2017

Published online: 25 January 2017 


\section{References}

1. Force ADT, Ranieri VM, Rubenfeld GD, Thompson BT, Ferguson ND, Caldwell E, Fan E, Camporota L, Slutsky AS. Acute respiratory distress syndrome: the Berlin definition. JAMA. 2012;307(23):2526-33.

2. ARDSnet. Ventilation with lower tidal volumes as compared with traditional tidal volumes for acute lung injury and the acute respiratory distress syndrome. The acute respiratory distress syndrome network. N Engl J Med. 2000;342(18):1301-8.

3. Guerin C, Reignier J, Richard JC, Beuret P, Gacouin A, Boulain T, Mercier E, Badet M, Mercat A, Baudin O, Clavel M, Chatellier D, Jaber S, Rosselli S, Mancebo J, Sirodot M, Hilbert G, Bengler C, Richecoeur J, Gainnier M, Bayle F, Bourdin G, Leray V, Girard R, Baboi L, Ayzac L, Group PS. Prone positioning in severe acute respiratory distress syndrome. N Engl J Med. 2013;368(23):2159-68.

4. Brodie D, Bacchetta M. Extracorporeal membrane oxygenation for ARDS in adults. N Engl J Med. 2011;365(20):1905-14.

5. Richard C, et al. Extracorporeal life support for patients with acute respiratory distress syndrome: report of a consensus conference. Ann Intensive Care. 2014:4:15

6. Fan E, Gattinoni L, Combes A, Schmidt M, Peek G, Brodie D, Muller T, Morelli A, Ranieri VM, Pesenti A, Brochard L, Hodgson C, Van Kiersbilck C, Roch A, Quintel M, Papazian L. Venovenous extracorporeal membrane oxygenation for acute respiratory failure: a clinical review from an international group of experts. Intensive Care Med. 2016;42(5):712-24.

7. Peek GJ, Mugford M, Tiruvoipati R, Wilson A, Allen E, Thalanany MM, Hibbert CL, Truesdale A, Clemens F, Cooper N, Firmin RK, Elbourne D, collaboration Ct. Efficacy and economic assessment of conventional ventilatory support versus extracorporeal membrane oxygenation for severe adult respiratory failure (CESAR): a multicentre randomised controlled trial. Lancet. 2009;374(9698):1351-63.

8. Davies A, Jones D, Bailey M, Beca J, Bellomo R, Blackwell N, Forrest P, Gattas D, Granger E, Herkes R, Jackson A, McGuinness S, Nair P, Pellegrino V, Pettila V, Plunkett B, Pye R, Torzillo P, Webb S, Wilson M, Ziegenfuss M. Extracorporeal membrane oxygenation for 2009 influenza A(H1N1) acute respiratory distress syndrome. JAMA. 2009;302(17):1888-95.

9. Ventetuolo CE, Muratore CS. Extracorporeal life support in critically ill adults. Am J Respir Crit Care Med. 2014;190(5):497-508.

10. Schmidt M, Bailey M, Sheldrake J, Hodgson C, Aubron C, Rycus PT, Scheinkestel C, Cooper DJ, Brodie D, Pellegrino V, Combes A, Pilcher D. Predicting survival after extracorporeal membrane oxygenation for severe acute respiratory failure. The respiratory extracorporeal membrane oxygenation survival prediction (RESP) score. Am J Respir Crit Care Med. 2014;189(11):1374-82

11. Del Sorbo L, Cypel M, Fan E. Extracorporeal life support for adults with severe acute respiratory failure. Lancet Respir Med. 2014;2:154-64.

12. Schmidt M, Pellegrino V, Combes A, Scheinkestel C, Cooper DJ, Hodgson C. Mechanical ventilation during extracorporeal membrane oxygenation. Crit Care. 2014;18:203.

13. Marhong JD, Telesnicki T, Munshi L, Del Sorbo L, Detsky M, Fan E. Mechanical ventilation during extracorporeal membrane oxygenation. An international survey. Ann Am Thorac Soc. 2014;11(6):956-61.

14. Marhong JD, Munshi L, Detsky M, Telesnicki T, Fan E. Mechanical ventilation during extracorporeal life support (ECLS): a systematic review. Intensive Care Med. 2015;41(6):994-1003.

15. Amato MB, Barbas CS, Medeiros DM, Magaldi RB, Schettino GP, LorenziFilho G, Kairalla RA, Deheinzelin D, Munoz C, Oliveira R, Takagaki TY, Carvalho CR. Effect of a protective-ventilation strategy on mortality in the acute respiratory distress syndrome. N Engl J Med. 1998;338(6):347-54.

16. Hager DN, Krishnan JA, Hayden DL, Brower RG, Network ACT. Tidal volume reduction in patients with acute lung injury when plateau pressures are not high. Am J Respir Crit Care Med. 2005;172:1241-5.

17. Amato MB, Meade MO, Slutsky AS, Brochard L, Costa EL, Schoenfeld DA Stewart TE, Briel M, Talmor D, Mercat A, Richard JC, Carvalho CR, Brower RG. Driving pressure and survival in the acute respiratory distress syndrome. N Engl J Med. 2015;372(8):747-55.

18. Baedorf Kassis E, Loring SH, Talmor D. Mortality and pulmonary mechanics in relation to respiratory system and transpulmonary driving pressures in ARDS. Intensive Care Med. 2016:42(8):1206-13.
19. Fanelli V, Ranieri MV, Mancebo J, Moerer O, Quintel M, Morley S, Moran I, Parrilla F, Costamagna A, Gaudiosi M, Combes A. Feasibility and safety of low-flow extracorporeal carbon dioxide removal to facilitate ultraprotective ventilation in patients with moderate acute respiratory distress sindrome. Crit Care. 2016:20:36.

20. Gattinoni L. Ultra-protective ventilation and hypoxemia. Crit Care. 2016;20:130.

21. Costa EL, Slutsky AS, Amato MB. Driving pressure as a key ventilation variable. N Engl J Med. 2015;372(21):2072.

22. Hess Dean R, Kacmarek Robert M. Essentials of Mechanical Ventilation. 3rd ed. New York: McGraw-Hill Education; 2014. p. 300-2.

23. Pham T, Combes A, Roze H, Chevret S, Mercat A, Roch A, Mourvillier B, Ara-Somohano C, Bastien O, Zogheib E, Clavel M, Constan A, Marie Richard JC, Brun-Buisson C, Brochard L, Network RR. Extracorporeal membrane oxygenation for pandemic influenza A(H1N1)-induced acute respiratory distress syndrome: a cohort study and propensity-matched analysis. Am J Respir Crit Care Med. 2013;187(3):276-85.

24. Schmidt M, Stewart C, Bailey M, Nieszkowska A, Kelly J, Murphy L, Pilcher D, Cooper DJ, Scheinkestel C, Pellegrino V, Forrest P, Combes A, Hodgson C. Mechanical ventilation management during extracorporeal membrane oxygenation for acute respiratory distress syndrome: a retrospective international multicenter study. Crit Care Med. 2015:43(3):654-64.

25. Schmidt M, Zogheib E, Roze H, Repesse X, Lebreton G, Luyt CE, Trouillet JL, Brechot N, Nieszkowska A, Dupont H, Ouattara A, Leprince P, Chastre J, Combes A. The PRESERVE mortality risk score and analysis of long-term outcomes after extracorporeal membrane oxygenation for severe acute respiratory distress syndrome. Intensive Care Med. 2013;39(10):1704-13.

26. Chiu LC, Tsai FC, Hu HC, Chang CH, Hung CY, Lee CS, Li SH, Lin SW, Li LF, Huang CC, Chen NH, Yang CT, Chen YC, Kao KC. Survival predictors in acute respiratory distress syndrome with extracorporeal membrane oxygenation. Ann Thorac Surg. 2015;99(1):243-50.

27. Brogan TV, Thiagarajan RR, Rycus PT, Bartlett RH, Bratton SL. Extracorporeal membrane oxygenation in adults with severe respiratory failure: a multi-center database. Intensive Care Med. 2009;35(12):2105-14.

28. Slutsky AS, Ranieri VM. Ventilator-induced lung injury. N Engl J Med. 2013:369(22):2126-36.

29. Pappalardo F, Pieri M, Greco T, Patroniti N, Pesenti A, Arcadipane A, Ranieri VM, Gattinoni L, Landoni G, Holzgraefe B, Beutel G, Zangrillo A, Italian E. Predicting mortality risk in patients undergoing venovenous ECMO for ARDS due to influenza A (H1N1) pneumonia: the ECMOnet score. Intensive Care Med. 2013;39(2):275-81.

30. Roch A, Hraiech S, Masson E, Grisoli D, Forel JM, Boucekine M, Morera P, Guervilly C, Adda M, Dizier S, Toesca R, Cart F, Papazian L. Outcome of acute respiratory distress syndrome patients treated with extracorporeal membrane oxygenation and brought to a referral center. Intensive Care Med. 2014:40(1):74-83.

\section{Submit your manuscript to a SpringerOpen ${ }^{\odot}$ journal and benefit from:}

- Convenient online submission

- Rigorous peer review

- Immediate publication on acceptance

- Open access: articles freely available online

- High visibility within the field

- Retaining the copyright to your article

Submit your next manuscript at springeropen.com 